\title{
Article
}

\section{The Association between Vigorous Physical Activity and Stress in Adolescents with Asthma}

\author{
Sunga Kong ${ }^{1,2} \mathbb{D}$, Wi-Young So ${ }^{3} \mathbb{D}$ and Seyong Jang ${ }^{4, *}$ \\ 1 Department of Clinical Research Design and Evaluation, SAIHST, Sungkyunkwan University, \\ Seoul 06351, Korea; sunga00kong@gmail.com \\ 2 Samsung Medical Center, Patient-Centered Outcomes Research Institute, Seoul 06351, Korea \\ 3 Sports Medicine Major, College of Humanities and Arts, Korea National University of Transportation, \\ Chungju 27469, Korea; wowso@ut.ac.kr \\ 4 Department of Taekwondo, College of Arts and Physical Education, Gachon University, \\ Seongnam 13120, Korea \\ * Correspondence: naganolala@gachon.ac.kr; Tel.: +82-31-750-5190; Fax: +82-31-750-5847
}

Citation: Kong, S.; So, W.-Y.; Jang, S. The Association between Vigorous Physical Activity and Stress in Adolescents with Asthma. Int. J. Environ. Res. Public Health 2021, 18 , 3467. https://doi.org/10.3390/ ijerph18073467

Academic Editor:

Germán Vicente-Rodríguez

Received: 31 January 2021

Accepted: 23 March 2021

Published: 26 March 2021

Publisher's Note: MDPI stays neutral with regard to jurisdictional claims in published maps and institutional affiliations.

Copyright: (c) 2021 by the authors. Licensee MDPI, Basel, Switzerland. This article is an open access article distributed under the terms and conditions of the Creative Commons Attribution (CC BY) license (https:// creativecommons.org/licenses/by/ $4.0 /)$.

\begin{abstract}
Asthma is a very common condition that affects $5-10 \%$ of the global population, and its prevalence is increasing. Vigorous physical activity (PA) is effective in improving cardiorespiratory fitness and managing stress. This study aimed to investigate the association between vigorous PA and stress among Korean adolescents with asthma using large-scale survey data. The questionnaire data of 57,303 adolescents were analyzed using raw data from the 2019 Korea Youth Risk Behavior Web-Based Survey. We performed logistic regression analysis to calculate the stress odds ratios (ORs) and 95\% confidence intervals (CIs) for asthma and non-asthma groups using models 1 and 2. We also performed logistic regression analysis to calculate the stress OR for the asthma group with vigorous PA and non-vigorous PA using models 1, 2, and 3. Model 1 was adjusted for age, sex, obesity, smoking, and alcohol status; model 2 was further adjusted for household income, academic achievement, and comorbidities. Model 3 was further adjusted for moderate activity and resistance exercise. The OR of stress was $20 \%$ higher in the asthma group than in the non-asthma group $(p<0.05)$. In the fully adjusted models, the OR for the non-asthma group with vigorous PA versus non-vigorous PA was 0.89 (95\% CI: 0.84-0.94). However, the OR for the asthma group with vigorous PA versus non-vigorous PA was 0.70 (95\% CI: 0.57-0.86), indicating that adolescents who engage in vigorous PA had lower stress in the asthma group $(p<0.05)$. This study demonstrated that adolescents with asthma had higher stress levels than those without asthma; however, vigorous PA was associated with lower stress. These effects were more pronounced in adolescents with asthma.
\end{abstract}

Keywords: adolescents; asthma; exercise; stress; vigorous physical activity

\section{Introduction}

Asthma is a very common condition that affects $5-10 \%$ of the global population [1], and its prevalence is increasing [2]. The prevalence of asthma among adolescents in the Republic of Korea increased from 2.7\% in 1995 to $7.5 \%$ in 2010 [3]. Asthma is a chronic respiratory disease that is characterized by airway hyper-responsiveness, inflammation, and airflow obstruction [4], all of which result in higher oxidative stress [5]. Many previous studies have demonstrated a link between asthma and mental health problems [6,7]. Stress has been associated with increased asthma prevalence in multiple studies of adults and children [8]. Stress can influence health beliefs and behaviors that may affect asthma management [9]. Therefore, asthma management must incorporate multiple factors.

A stress management model is needed for asthma management [10]. Asthma that is associated with mental health problems leads to more frequent healthcare utilization by these patients, increasing the healthcare requirement for this condition [11]. The management of stress-including the burden of psychological distress-has been recognized 
as an important health determinant for both adults and adolescents [11,12]. According to Statistics Korea, in 2018, the intensity of stress for Korean adolescents was as high as $39.8 \%$ in 2017, and 4 out of 10 Korean adolescents still experience high levels of stress [13]. Such exposure to stress can be particularly harmful for adolescents because they are highly vulnerable to the effects of chronic stress at this sensitive and critical period of adolescent development [14]. Therefore, the management of stress for adolescents with asthma should be a priority along with mental healthcare.

There are several stress management programs; however, physical activity (PA) provides specific psychological treatment that may be particularly effective for patients for whom more conventional psychological interventions are less appropriate [15]. Furthermore, PA as a modifiable factor is reported to be the strongest variable associated with respiratory disease and greatly affects physiological age, dyspnea, airflow obstruction index, body mass index (BMI), airway obstruction, dyspnea, exercise capacity index, forced expiratory volume in one second \% $\left(\mathrm{FEV}_{1}\right)$, and 6-min walk distance [16]. Previous research has indicated that PA has a positive effect on mental health and improves asthmatic symptoms in patients with asthma. Furthermore, the amount of sedentary time has been found to influence the prevalence of asthma in Korean adolescents [17].

However, previous studies on the management of asthma used small sample sizes, and the sample population was usually limited to adult [18] or pediatric patients [19,20]. Studies on the association between exercise, such as vigorous PA, and stress among adolescents with asthma are unavailable [21]. Vigorous PA is particularly more effective in strengthening cardiorespiratory fitness [22] compared with moderate activity; however, no study has confirmed its effect by evaluating vigorous PA in adolescents. Additionally, in this field, large-scale research is necessary for proactive healthcare for adolescents [23]. Thus, this study analyzed the association between vigorous PA and stress in adolescents with asthma using the data from a large-scale survey of Korean adolescents.

\section{Materials and Methods}

\subsection{Participants}

This cross-sectional study used raw data from the 2019 Korea Youth Risk Behavior Web-Based Survey (KYRBWS)-15 ${ }^{\text {th }}$, which was a self-administered, online, statistical survey that was approved by the Korean government to understand the health behavior of Korean middle and high school students (7th-12th grade). Of the total 60,100 survey participants, $57,303(95.3 \%)$ were analyzed in the current study. Since private or identifiable information such as telephone numbers, social security numbers, and home addresses was not collected by the KYRBWS-XV, ethical approval was not required for this study. Furthermore, all research procedures were controlled and approved by the Korea Centers for Disease Control and Prevention (KCDCP) and conducted in accordance with the principles outlined in the Declaration of Helsinki. All the details pertaining to data collection procedures have been reported by the KCDCP [24], and the reliability and validity of the KYRBWS questionnaires have been evaluated $[25,26]$.

\subsection{Definition of Groups}

If the participant responded "yes" to the question "Did a doctor ever say that you had asthma?", this participant was allocated to the asthma group. If the participants responded "no" or "don't know", they were allocated to the non-asthma group. Participants were assigned to the non-vigorous PA group if they responded "no exercise", " 1 day", or " 2 days" to the question "In the last 7 days, how many days did you do vigorous PA that caused you to be out of breath or sweat for more than 20 min?" Participants were allocated to the vigorous PA group if they answered " 3 days", " 4 days", or "more than 5 days" to this question [27]. 


\subsection{Main Outcome}

Participants who responded "very often," "often," or "seldom" to the question "How often do you feel stress?" were assigned to the stress category, and those who answered "very seldom" or "never" were assigned to the non-stress category.

\subsection{Covariate Variables}

Sociodemographic characteristics included age, sex, BMI, and grade (middle or high school). Smoking status was classified using the responses "no" and "yes" to the question "Have you ever smoked (even once) in the past?" Alcohol consumption was classified using the responses "no" and "yes" to the question "Have you ever drunk more than one glass of alcohol?"

Economic status included household income and was classified as "high," "medium high," "medium," "medium low," or "low" based on the response to the question "How would you classify your family's economic status?" Academic achievement was classified as "high," "medium high," "medium," "medium low," or "low" based on the response to the question "How was your academic achievement over the past 12 months?"

Health-related PA included moderate activity and resistance exercise. Moderate activity was classified using the responses "no exercise," " 1 day," "2 days," " 3 days," " 4 days," or "more than 5 days" to the question "In the last 7 days, on how many days did you do PA (regardless of type) for more than $60 \mathrm{~min}$ that resulted in an accelerated heart rate or feeling out of breath?" Resistance exercise was classified using the responses "no resistance exercise," " 1 day," "2 days," " 3 days," " 4 days," or "more than 5 days" to the question "In the last 7 days, on how many days did you do resistance exercises such as push-ups, sit-ups, lifting dumbbells and barbells, chin-ups, or use of parallel bars?"

\subsection{Statistical Analyses}

All analyses were conducted using the STATA software, version 15.0 (STATA Corp., College Station, TX, USA). All variables were expressed as mean, standard deviation, and percentages (\%). The characteristics of the groups (non-asthma and asthma) were compared using an independent $t$-test and a Chi-square test. These tests were conducted to analyze different physical characteristics, smoking status, alcohol consumption, household income, academic achievement, moderate activity, vigorous PA, and resistance exercise in relation to asthma. The stress odds ratios (ORs) (95\% confidence interval (CI)) according to the frequency of vigorous PA was calculated using logistic regression. The stress OR according to the asthma group and the vigorous PA group was calculated using multiple logistic regression with models 1 and 2 . The OR (95\% CI) of stress according to vigorous PA versus non-vigorous PA in the asthma and non-asthma groups was calculated using multiple logistic regression with models 1,2 , and 3 . Model 1 was adjusted for age, sex, and obesity (BMI of $<18.5,18.5-22.9$, and $\leq 23 \mathrm{~km} / \mathrm{m}^{2}$ ); model 2 was further adjusted for household income ( $<$ medium-high and $\geq$ medium-high), academic achievement $(<$ medium-high and $\geq$ medium-high), and comorbidities (atopic dermatitis or allergic rhinitis); and model 3 was further adjusted for resistance exercise ( $<3$ days per week or $\geq 3$ days per week) and moderate activity ( $<5$ days per week or $\geq 5$ days per week). All statistical significance was set at $p<0.05$.

\section{Results}

The characteristics of the asthma and non-asthma groups are shown in Table 1. Of the total 57,303 participants, $4020(7.02 \%)$ were assigned to the asthma group. The asthma group was older, had a $5.5 \%$ higher male-to-female ratio, and had a $0.6 \mathrm{~kg} / \mathrm{m}^{2}$ higher BMI than the non-asthma group $(p<0.001)$. Academic achievement was better in the asthma group than in the non-asthma group $(p<0.001)$. Moderate activity and resistance exercise were significantly higher in the asthma group $(p<0.05)$. No significant differences in vigorous PA were found between the groups $(p>0.05)$ (Table 1$)$. 
Table 1. Characteristics of participants with asthma and without asthma.

\begin{tabular}{|c|c|c|c|c|}
\hline Variables. & Total $(n=57,303)$ & Asthma $(n=4020)$ & $\begin{array}{l}\text { Non-Asthma } \\
(n=53,283)\end{array}$ & $p$ \\
\hline Age (year) & $15.0(1.8)$ & $15.1(1.7)$ & $15.0(1.8)$ & $<0.001^{* * *}$ \\
\hline Male, $\mathrm{N}(\%)$ & $29,841(52.1)$ & $2300(57.2)$ & $27,541(51.7)$ & $<0.001^{* * *}$ \\
\hline Body mass index $\left(\mathrm{kg} / \mathrm{m}^{2}\right)$ & $21.4(3.6)$ & $21.9(3.7)$ & $21.3(3.5)$ & $<0.001^{* * *}$ \\
\hline Grade $(\%)$ & & & & $<0.001^{* * *}$ \\
\hline Middle school & 51.3 & 47.4 & 51.6 & \\
\hline High school & 48.7 & 52.6 & 48.4 & \\
\hline Smoking status (\%) & & & & $<0.001^{* * *}$ \\
\hline No & 87.7 & 84.3 & 89.9 & \\
\hline Yes & 12.3 & 15.7 & 12.1 & \\
\hline Alcohol consumption (\%) & & & & $<0.001^{* * *}$ \\
\hline No & 61.2 & 56.6 & 61.5 & \\
\hline Yes & 38.8 & 43.4 & 38.5 & \\
\hline Household income (\%) & & & & 0.281 \\
\hline High or medium-high & 39.3 & 40.1 & 39.2 & \\
\hline Medium, medium-low, or low & 60.7 & 59.9 & 60.8 & \\
\hline Academic achievement $(\%)$ & & & & $0.001 * *$ \\
\hline High or medium-high & 38.3 & 40.7 & 38.1 & \\
\hline Medium, medium-low, or low & 61.7 & 59.3 & 61.9 & \\
\hline Moderate physical activity (\%) & & & & 0.021 * \\
\hline$<5$ times per week & 15.2 & 83.4 & 84.8 & \\
\hline$\geq 5$ times per week & 84.8 & 16.6 & 15.2 & \\
\hline Vigorous physical activity (\%) & & & & 0.064 \\
\hline$<3$ days per week & 67.1 & 65.8 & 67.2 & \\
\hline$\geq 3$ days per week & 32.9 & 34.2 & 32.8 & \\
\hline Resistance exercise (\%) & & & & $0.004^{* *}$ \\
\hline None or once per week & 67.3 & 65.2 & 67.4 & \\
\hline$\geq 2$ times per week & 32.7 & 34.8 & 32.6 & \\
\hline
\end{tabular}

iLogistic regression was used to determine the relationship of stress with the frequency of vigorous PA. The OR was significantly decreased when vigorous PA was performed for more than three days a week, 0.87 (0.82-0.93); more than four days a week, $0.79(0.72-0.87)$; and more than five days a week, $0.76(0.71-0.81)(p<0.05)$ (Figure 1$)$.

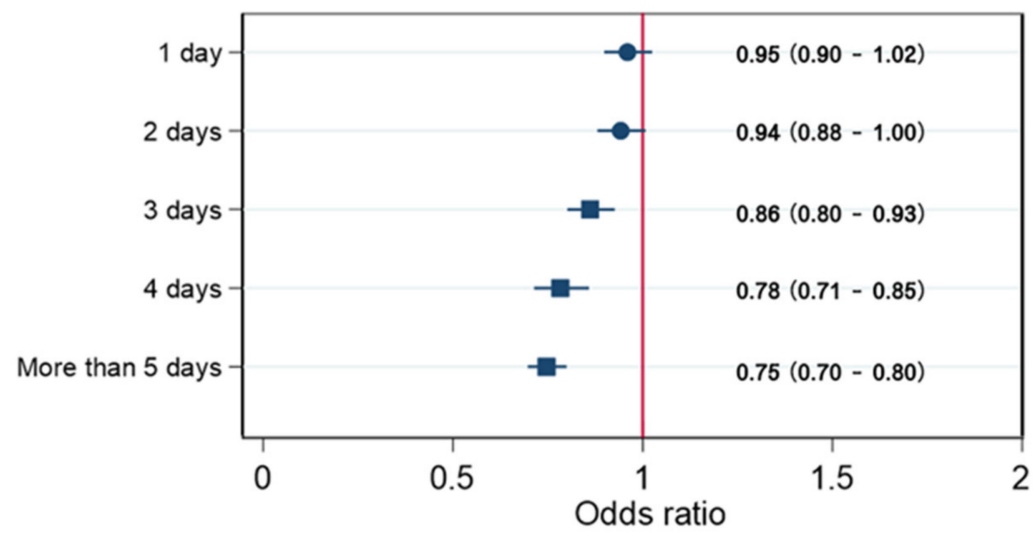

Figure 1. Odds ratios (95\% confidence interval (CI)) of stress in relation to vigorous physical activity.

This figure shows the OR (95\% CI) of stress in relation to vigorous physical activity, adjusted for age, sex, obesity (BMI of $<18.5,18.5-22.9$, and $\leq 23 \mathrm{~kg} / \mathrm{m}^{2}$ ), smoking status, and alcohol status.

In relation to stress, the asthma group had an OR of 1.24 (1.14-1.36) in model 1 and an OR of 1.14 (1.04-1.25) in model 2. This group had a higher OR than the non-asthma group 
$(p<0.05)$. Conversely, the vigorous PA group had an OR of $0.82(0.78-0.86)$ in model 1 and an OR of $0.84(0.80-0.88)$ in model 2 . The OR of this group had a lower OR than that of the non-vigorous PA group $(p<0.05)$ (Table 2).

Table 2. Odds ratios of stress status in relation to asthma or vigorous physical activity.

\begin{tabular}{|c|c|c|c|c|c|c|}
\hline Variables. & Non-Asthma & Asthma & $p$ & $\begin{array}{c}\text { Non-Vigorous } \\
\text { Physical } \\
\text { Activity }\end{array}$ & $\begin{array}{l}\text { Vigorous } \\
\text { Physical } \\
\text { Activity }\end{array}$ & $p$ \\
\hline \multicolumn{7}{|l|}{ Stress } \\
\hline $\begin{array}{c}\text { a Model } 1 \text { OR } \\
(95 \% \text { CI })\end{array}$ & Reference & $1.24(1.14-1.36)$ & $<0.001^{* * *}$ & Reference & $0.82(0.78-0.86)$ & $<0.001^{* * *}$ \\
\hline 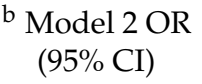 & Reference & $1.14(1.04-1.25)$ & $0.004^{* *}$ & Reference & $0.84(0.80-0.88)$ & $<0.001^{* * *}$ \\
\hline
\end{tabular}

OR: Odd ratio; CI: confidence interval; BMI: body mass index. ${ }^{* *} p<0.01,{ }^{* * *} p<0.001$; tested by multiple logistic regression analysis. a Model 1: adjusted for age, sex, obesity (BMI of $<18.5,18.5-22.9$, and $\leq 23 \mathrm{~kg} / \mathrm{m}^{2}$ ), smoking status, and alcohol consumption. ${ }^{\mathrm{b}}$ Model 2: further adjusted for household income ( $<$ medium-high and $\geq$ medium-high), academic achievement ( $<$ medium-high and $\geq$ medium-high), and comorbidities (atopic dermatitis or allergic rhinitis).

The non-asthma group that engaged in vigorous PA displayed an OR of 0.82 (0.790.86 ) in model 1 , an OR of $0.84(0.80-0.88)$ in model 2 , and an OR of $0.89(0.84-0.94)$ in model 3. This group had a lower OR than the non-vigorous PA group. The asthma group with vigorous PA had an OR of $0.77(0.64-0.92)$ in model 1, an OR of $0.78(0.65-0.93)$ in model 2, and an OR of $0.70(0.57-0.86)$ in model 3. This group had a lower OR than the non-vigorous PA group $(p<0.05)$ (Table 3$)$.

Table 3. Odds ratios of stress status in relation to asthma and vigorous physical activity.

\begin{tabular}{|c|c|c|c|c|c|c|}
\hline Variables. & $\begin{array}{l}\text { Non-Asthma } \\
\text { Non-Vigorous }\end{array}$ & $\begin{array}{c}\text { Non-Asthma } \\
\text { Vigorous }\end{array}$ & $p$ & $\begin{array}{c}\text { Asthma } \\
\text { Non-Vigorous } \\
\text { Physical } \\
\text { Activity }\end{array}$ & $\begin{array}{c}\text { Asthma } \\
\text { Vigorous } \\
\text { Physical } \\
\text { Activity }\end{array}$ & $p$ \\
\hline $\begin{array}{c}\text { Stress } \\
\text { a Model 1 OR } \\
(95 \% \text { CI })\end{array}$ & Reference & $0.82(0.79-0.86)$ & $<0.001^{* * *}$ & Reference & $0.77(0.64-0.92)$ & $0.005^{* *}$ \\
\hline $\begin{array}{c}\text { b Model } 2 \text { OR } \\
(95 \% \text { CI })\end{array}$ & Reference & $0.84(0.80-0.88)$ & $<0.001^{* * *}$ & Reference & $0.78(0.65-0.93)$ & $0.006^{* *}$ \\
\hline $\begin{array}{c}{ }^{c} \text { Model } 3 \text { OR } \\
(95 \% \text { CI })\end{array}$ & Reference & $0.89(0.84-0.94)$ & $<0.001^{* * *}$ & Reference & $0.70(0.57-0.86)$ & $0.001^{* *}$ \\
\hline
\end{tabular}

OR: Odd ratio; CI: confidence interval; BMI: body mass index. ${ }^{* *} p<0.01,{ }^{* * *} p<0.001$; tested by multiple logistic regression analysis. a Model 1: adjusted for age, sex, obesity (BMI of $<18.5,18.5-22.9$, and $\leq 23 \mathrm{~kg} / \mathrm{m}^{2}$ ), smoking status, and alcohol consumption. ${ }^{\mathrm{b}}$ Model 2: further adjusted for household income (<medium-high and $\geq$ medium-high), academic achievement ( $<$ medium-high and $\geq$ medium-high), and comorbidities (atopic dermatitis or allergic rhinitis). ${ }^{c}$ Model 3: further adjusted for resistance exercise (yes or no; yes $=3$ or more time per week) and moderate activity (yes or no; yes $=5$ or more time per week).

\section{Discussion}

This study used data from a large-scale survey of Korean adolescents and revealed that adolescents with asthma had higher stress levels than those without asthma. However, more than 20 min of vigorous PA for more than three days a week resulted in lower stress among these participants. Vigorous PA was related to low levels of stress, but adolescents with asthma experienced lower stress than those without asthma.

In this study, adolescents with asthma displayed 1.24 and 1.14-fold higher stress levels than adolescents without asthma following adjustments in models 1 and 2, respectively. These results were consistent with the results of previous studies [28,29]. A previous study reported that emotional stress can promote or exacerbate acute and chronic asthma [29]. Another study that followed-up 326 adults for over a year revealed that higher perceived stress is correlated with worse asthma control and poor quality of life [30]. Since $39.8 \%$ of Korean adolescents reported a perception of stress in 2017 [13], customized health 
management for adolescents with asthma is necessary because adolescents with asthma are more vulnerable to stress than those without asthma.

In this study, the OR of stress in relation to the frequency of vigorous PA was identified in order to examine the association between vigorous PA and lower levels of stress among adolescents. Several studies have demonstrated a strong correlation between stress and PA among healthy adolescents [31-33]. However, the effect of PA on stress varies according to the intensity of the exercise. Moderate activity alone was also effective in reducing stress among adolescents [31]; however, these results were not consistent with those for light physical activity [34]. Stress affects physical and mental health and can cause distress-related depression and suicide, difficulty in sleeping, cardiovascular disease, and immune system dysfunction. Adolescents with mental disorders can have severe social and occupational dysfunction in adulthood [35]. Many studies have demonstrated the positive effect of exercise and PA on mental health [31-36]. Furthermore, our study demonstrated that $>20$ min of vigorous PA for more than three times a week was related to low stress levels among adolescents.

Finally, our study detected that regular vigorous PA, despite higher stress levels in the asthma group, had a lower impact on adolescents with asthma than on those without asthma. These results are consistent with the results of previous studies. Adolescent PA guidelines recommend more than $60 \mathrm{~min}$ of daily moderate-to-vigorous PA with additional vigorous PA more than three times per week [37]. Our results indicated that vigorous PA was an independent factor that lowered stress among adolescents with asthma after adjusting for exercise behavior. Oxidative stress is recognized as a burden in patients with asthma and is one of the risk factors that induces and exacerbates respiratory diseases, such as atherosclerosis, cardiovascular disease, chronic obstructive pulmonary disease, and bronchial asthma [38-40]. Further, oxidative stress is linked to emotional stress [41]. However, there is evidence that exercise increases antioxidant protection among adolescents [42]. Structured exercise programs were found to result in better lung function in asthmatic children, potentially due to the antioxidant effect of PA [20]. Our results cannot suggest that regular vigorous PA actually had an antioxidant effect on adolescents; however, clinically, progressive vigorous PA will be helpful in reinforcing cardiorespiratory function in adolescents [27], reducing oxidative stress [43], and improving physical and psychological stress [44]. Our results, although specifically for adolescents with asthma, confirmed that regular vigorous PA is associated with less stress than irregular PA, despite the fact that the cause is not clear. However, physical fitness and the maintenance of healthy body weight may actually reduce the symptoms of asthma and could help control the disease $[45,46]$. Furthermore, fitness levels, including cardiorespiratory fitness, among adolescents with asthma are lower than those among adolescents without asthma [47]. In addition to encouraging simple physical activity, a program to improve cardiopulmonary function through high-intensity exercise is needed.

This study had several limitations. First, this study was based on a questionnaire survey; therefore, a history of asthma treatment and severity could not be determined. Additionally, some participants may not have been clinically diagnosed but still may have experienced some symptoms of asthma. However, the incidence rate of asthma among Korean adolescents is approximately $7 \%$, and this sample demonstrated a prevalence of $7.05 \%$, which was similar to the domestic criteria. Second, this study was conducted online using multiple-choice questions; therefore, it is possible that the exact amount of vigorous PA and self-reported PA may have varied. However, our data identified moderate and resistance strengthening exercises, thus enabling the classification of the intensity and type of exercise. Third, racial and socioeconomic differences may have existed, and these factors were not considered in this study. Fourth, this study was a cross-sectional study with a retrospective cohort design. Therefore, we did not examine cause and effect-only interrelationships. Nevertheless, this study had the advantage of being a governmentoriented large survey with 57,303 participants. 


\section{Conclusions}

In this study, stress was higher among adolescents with asthma than adolescents without asthma. However, more than 20 min of vigorous PA more than three times a week was demonstrated to lower stress, and the association between stress and vigorous PA was more pronounced for adolescents with asthma than those without asthma. It is therefore necessary to emphasize the importance of vigorous PA for adolescents with elevated stress along with respiratory diseases such as asthma.

Author Contributions: Study design: S.K. and S.J. Study conduct: S.K., S.J., and W.-Y.S. Data collection: S.K. and S.J. Data analysis: S.K. and S.J. Data interpretation: S.K., S.J., and W.-Y.S. Drafting the manuscript: S.K., S.J., and W.-Y.S. Revising the manuscript content: S.K., S.J., and W.-Y.S. All authors have read and agreed to the published version of the manuscript.

Funding: This research received no external funding.

Institutional Review Board Statement: Since data from the 2019 Korea Youth Risk Behavior WebBased Survey did not include private identifier information, ethical approval was not required. The study was approved by the Korea Centers for Disease Control and Prevention, and ethical approval was waived.

Informed Consent Statement: Informed consent was obtained from all subjects involved in the study.

Data Availability Statement: The data that support the findings of this study are openly available in Korea Centers for Disease Control and Prevention in May 25, 2020 at http://yhs.cdc.go.kr/.

Conflicts of Interest: The authors declare no conflict of interest.

\section{References}

1. Akinbami, L.J.; Simon, A.E.; Rossen, L.M. Changing Trends in Asthma Prevalence Among Children. Pediatrics 2016, 137, e20152354-7. [CrossRef] [PubMed]

2. Cohen, A.J.; Brauer, M.; Burnett, R.; Anderson, H.R.; Frostad, J.; Estep, K.; Balakrishnan, K.; Brunekreef, B.; Dandona, L.; Dandona, R.; et al. Estimates and 25-year trends of the global burden of disease attributable to ambient air pollution: An analysis of data from the Global Burden of Diseases Study 2015. Lancet 2017, 389, 1907-1918. [CrossRef]

3. Lee, E.; Kim, A.; Ye, Y.-M.; Choi, S.-E.; Park, H.-S. Increasing Prevalence and Mortality of Asthma with Age in Korea, 2002-2015: A Nationwide, Population-Based Study. Allergy Asthma Immunol. Res. 2020, 12, 467-484. [CrossRef]

4. Hoogsteden, H.C.; Verhoeven, G.T.; Lambrecht, B.N.; Prins, J.-B. Airway inflammation in asthma and chronic obstructive pulmonary disease with special emphasis on the antigen-presenting dendritic cell: Influence of treatment with fluticasone propionate. Clin. Exp. Allergy 1999, 29 (Suppl. 2), 116-124. [CrossRef] [PubMed]

5. Kirkham, P.; Rahman, I. Oxidative stress in asthma and COPD: Antioxidants as a therapeutic strategy. Pharmacol. Ther. 2006, 111, 476-494. [CrossRef] [PubMed]

6. Goodwin, R.D.; Bandiera, F.C.; Steinberg, D.; Ortega, A.N.; Feldman, J.M. Asthma and mental health among youth: Etiology, current knowledge and future directions. Expert Rev. Respir. Med. 2012, 6, 397-406. [CrossRef]

7. Wright, R.J; Rodriguez, M.; Cohen, S. Review of psychosocial stress and asthma: An integrated biopsychosocial approach. Thorax 1998, 53, 1066-1074. [CrossRef]

8. Yonas, M.A.; Lange, N.E.; Celedón, J.C. Psychosocial stress and asthma morbidity. Curr. Opin. Allergy Clin. Immunol. 2012, 12, 202-210. [CrossRef]

9. Gupta, A.; Bhat, G.; Pianosi, P. What is New in the Management of Childhood Asthma? Indian J. Pediatrics 2018, 85, 773-781. [CrossRef]

10. Landeo-Gutierrez, J.; Celedón, J.C. Chronic stress and asthma in adolescents. Ann. Allergy Asthma Immunol. 2020, 125, 393-398. [CrossRef]

11. Becerra, B.J.; Becerra, M.B. Association between asthma and serious psychological distress among male veterans compared to civilian counterparts. Prev. Med. 2015, 71, 8-11. [CrossRef] [PubMed]

12. Smith, H.E.; Jones, C.J. Psychological Interventions in Asthma. Curr. Treat. Options Allergy 2015, 2, 155-168. [CrossRef]

13. Korea, S. Youth Statistics; KOSIS: Daejeon, Korea, 2019.

14. Fox, S.E.; Levitt, P.; Iii, C.A.N. How the Timing and Quality of Early Experiences Influence the Development of Brain Architecture. Child. Dev. 2010, 81, 28-40. [CrossRef] [PubMed]

15. Salmon, P. Effects of physical exercise on anxiety, depression, and sensitivity to stress: A unifying theory. Clin. Psychol. Rev. 2001, 21, 33-61. [CrossRef]

16. Waschki, B.; Kirsten, A.; Holz, O.; Müller, K.; Meyer, T.; Watz, H.; Magnussen, H. Physical activity is the strongest predictor of all-cause mortality in patients with COPD: A prospective cohort study. Chest 2011, 140, 331-342. [CrossRef] 
17. Kim, J.-W.; So, W.-Y.; Kim, Y.S. Association between asthma and physical activity in Korean adolescents: The 3rd Korea Youth Risk Behavior Web-based Survey (KYRBWS-III). Eur. J. Public Health 2011, 22, 864-868. [CrossRef] [PubMed]

18. Heikkinen, S.A.M.; Mäkikyrö, E.M.S.; Hugg, T.T.; Jaakkola, M.S.; Jaakkola, J.J.K. Effects of regular exercise on asthma control in young adults. J. Asthma 2017, 55, 726-733. [CrossRef] [PubMed]

19. Vahlkvist, S.; Inman, M.D.; Pedersen, S. Effect of asthma treatment on fitness, daily activity and body composition in children with asthma. Allergy 2010, 65, 1464-1471. [CrossRef]

20. Onur, E.; Kabaroğlu, C.; Günay, Ö.; Var, A.; Yilmaz, Ö.; Dündar, P.; Tikiz, C.; Güvenç, Y.; Yüksel, H. The beneficial effects of physical exercise on antioxidant status in asthmatic children. Allergol. Immunopathol. 2011, 39, 90-95. [CrossRef]

21. Gallego, J.; Aguilar-Parra, J.M.; Cangas, A.J.; Langer, Á.I.; Mañas, I. Effect of a Mindfulness Program on Stress, Anxiety and Depression in University Students. Span. J. Psychol. 2014, 17, E109. [CrossRef] [PubMed]

22. Moore, J.B.; Beets, M.W.; Barr-Anderson, D.J.; Evenson, K.R. Sedentary time and vigorous physical activity are independently associated with cardiorespiratory fitness in middle school youth. J. Sports Sci. 2013, 31, 1520-1525. [CrossRef]

23. Yamasaki, A.; Kawasaki, Y.; Takeda, K.; Harada, T.; Hasegawa, Y.; Fukushima, T.; Okazaki, R.; Makino, H.; Funaki, Y.; Sueda, Y.; et al. Relationship between Oxidative Stress, Physical Activity, and Vitamin Intake in Patients with Asthma. Yonago Acta Medica 2017, 60, 86-93. [CrossRef]

24. Korea Centers for Disease Control and Prevention. The Statistics of 15th Korea Youth Risk Behavior Web-Based Survey (KYRBWS) in 2019; Korea Centers for Disease Control and Prevention: Cheongju-si, Korea, 2019.

25. Bae, J.; Joung, H.; Kim, J.-Y.; Kwon, K.N.; Kim, Y.; Park, S.-W. Validity of Self-Reported Height, Weight, and Body Mass Index of the Korea Youth Risk Behavior Web-Based Survey Questionnaire. J. Prev. Med. Public Health 2010, 43, 396-402. [CrossRef] [PubMed]

26. Bae, J.; Joung, H.; Kim, J.-Y.; Kwon, K.N.; Kim, Y.T.; Park, S.-W. Test-Retest Reliability of a Questionnaire for the Korea Youth Risk Behavior Web-Based Survey. J. Prev. Med. Public Health 2010, 43, 403-410. [CrossRef] [PubMed]

27. Twisk, J.W.R. Physical Activity Guidelines for Children and Adolescents. Sports Med. 2001, 31, 617-627. [CrossRef] [PubMed]

28. Oh, Y.-M.; Kim, Y.S.; Yoo, S.H.; Kim, S.K.; Kim, D.S. Association between stress and asthma symptoms: A population-based study. Respirology 2004, 9, 363-368. [CrossRef] [PubMed]

29. Van Lieshout, R.J.; MacQueen, G. Psychological Factors in Asthma. Allergy Asthma Clin. Immunol. 2008, 4, 12-17. [CrossRef]

30. Wisnivesky, J.P.; Lorenzo, J.; Feldman, J.M.; Leventhal, H.; Halm, E.A. The relationship between perceived stress and mor-bidity among adult inner-city asthmatics. J. Asthma 2010, 47, 100-104. [CrossRef]

31. Norris, R.; Carroll, D.; Cochrane, R. The effects of physical activity and exercise training on psychological stress and well-being in an adolescent population. J. Psychosom. Res. 1992, 36, 55-65. [CrossRef]

32. Bonhauser, M.; Fernandez, G.; Püschel, K.; Yañez, F.; Montero, J.; Thompson, B.; Coronado, G. Improving physical fitness and emotional well-being in adolescents of low socioeconomic status in Chile: Results of a school-based controlled trial. Health Promot. Int. 2005, 20, 113-122. [CrossRef]

33. Baghurst, T.; Kelley, B.C. An Examination of Stress in College Students Over the Course of a Semester. Health Promot. Pr. 2014, 15, 438-447. [CrossRef]

34. Khalsa, S.B.S.; Hickey-Schultz, L.; Cohen, D.; Steiner, N.; Cope, S. Evaluation of the Mental Health Benefits of Yoga in a Sec-ondary School: A Preliminary Randomized Controlled Trial. J. Behav. Health Serv. Res. 2012, 39, 80-90. [CrossRef] [PubMed]

35. Scott, E.M.; Hermens, D.F.; Glozier, N.; Naismith, S.L.; Guastella, A.J.; Hickie, I.B. Targeted primary care-based mental health services for young Australians. Med. J. Aust. 2012, 196, 136-140. [CrossRef] [PubMed]

36. O'Dougherty, M.; Hearst, M.O.; Syed, M.; Kurzer, M.S.; Schmitz, K.H. Life events, perceived stress and depressive symptoms in a physical activity intervention with young adult women. Ment. Health Phys. Act. 2012, 5, 148-154. [CrossRef] [PubMed]

37. Janssen, I. Physical activity guidelines for children and youth. Can. J. Public Health 2007, 98 (Suppl. 2), S109-S121.

38. Siti, H.N.; Kamisah, Y.; Kamsiah, J. The role of oxidative stress, antioxidants and vascular inflammation in cardiovascular disease (a review). Vasc. Pharmacol. 2015, 71, 40-56. [CrossRef]

39. Kim, H.; Yun, J.; Kwon, S.-M. Therapeutic Strategies for Oxidative Stress-Related Cardiovascular Diseases: Removal of Excess Reactive Oxygen Species in Adult Stem Cells. Oxidative Med. Cell. Longev. 2016, 2016, 2483163. [CrossRef]

40. Sugiura, H.; Ichinose, M. Oxidative and Nitrative Stress in Bronchial Asthma. Antioxid. Redox Signal. 2008, 10, 785-798. [CrossRef]

41. Bouayed, J.; Rammal, H.; Soulimani, R. Oxidative Stress and Anxiety: Relationship and Cellular Pathways. Oxidative Med. Cell. Longev. 2009, 2, 63-67. [CrossRef] [PubMed]

42. Leeuwenburgh, C.; Heinecke, J.W. Oxidative stress and antioxidants in exercise. Curr. Med. Chem. 2001, 8, 829-838. [CrossRef] [PubMed]

43. Polidori, M.C.; Mecocci, P.; Cherubini, A.; Senin, U. Physical Activity and Oxidative Stress During Aging. Int. J. Sports Med. 2000, 21, 154-157. [CrossRef] [PubMed]

44. Pascoe, M.; Bailey, A.P.; Craike, M.; Carter, T.; Patten, R.; Stepto, N.; Parker, A. Physical activity and exercise in youth mental health promotion: A scoping review. BMJ Open Sport Exerc. Med. 2020, 6, e000677. [CrossRef] [PubMed]

45. Welsh, L.; Roberts, R.G.D.; Kemp, J.G. Fitness and Physical Activity in Children with Asthma. Sports Med. 2004, 34, 861-870. [CrossRef] 
46. Tantisira, K.G.; Weiss, S.T. Complex interactions in complex traits: Obesity and asthma. Thorax 2001, 56, 64-73.

47. Welsh, L.; Kemp, J.G.; Roberts, R.G.D. Effects of Physical Conditioning on Children and Adolescents with Asthma. Sports Med. 2005, 35, 127-141. 